is the one describing the nesting habits of the two species of sand-plover which frequent the shore on False Bay and in the neighbourhood of Port Elizabeth. The visitor unaccustomed to the ways of these birds always fails at first to discover their eggs, although he may be convinced that they are in his immediate vicinity.

After one or two attempts, says the author, you retire and resolve to watch more carefully. "The bird soon returns to the same spot, shuffles for a second or two very quickly with its feet, and then sits down. This time you make no mistake about the exact place, and you locate the position of the bird with the aid of two little bits of herbage growing near; again you approach, the bird rises as before, and repeats the same performance, standing a little way off, and looking as though it would help you if it could, and if you would only tell it what you were looking for. The ground is quite undisturbed, and there is no sign of a nest or eggs ; the little bits of driftwood and bark, though, which lie between your feet are loose, and nomenclature, so that ornithologists may be satisfied that the various birds alluded to are correctly identified.

R. L.

\section{THE REPORT OF THE THOMPSON YATES LABORATORIES.}

THE Thompson Yates Laboratories Report, lately 1 published, edited by Profs. Rubert Boyce and C. S. Sherrington, is a worthy successor to the preceding volumes, which have previously been reviewed in these columns. The distribution of $B$. coli commune is the title of the first paper, by Miss Chick, who concludes that this organism is not so generally distributed as has been considered by some bacteriologists, and that its presence may be looked upon as useful evidence of recent fæcal contamination. Her experiments show the very low resistance which the $B$. coli can offer to unfavourable conditions, especially desiccation.

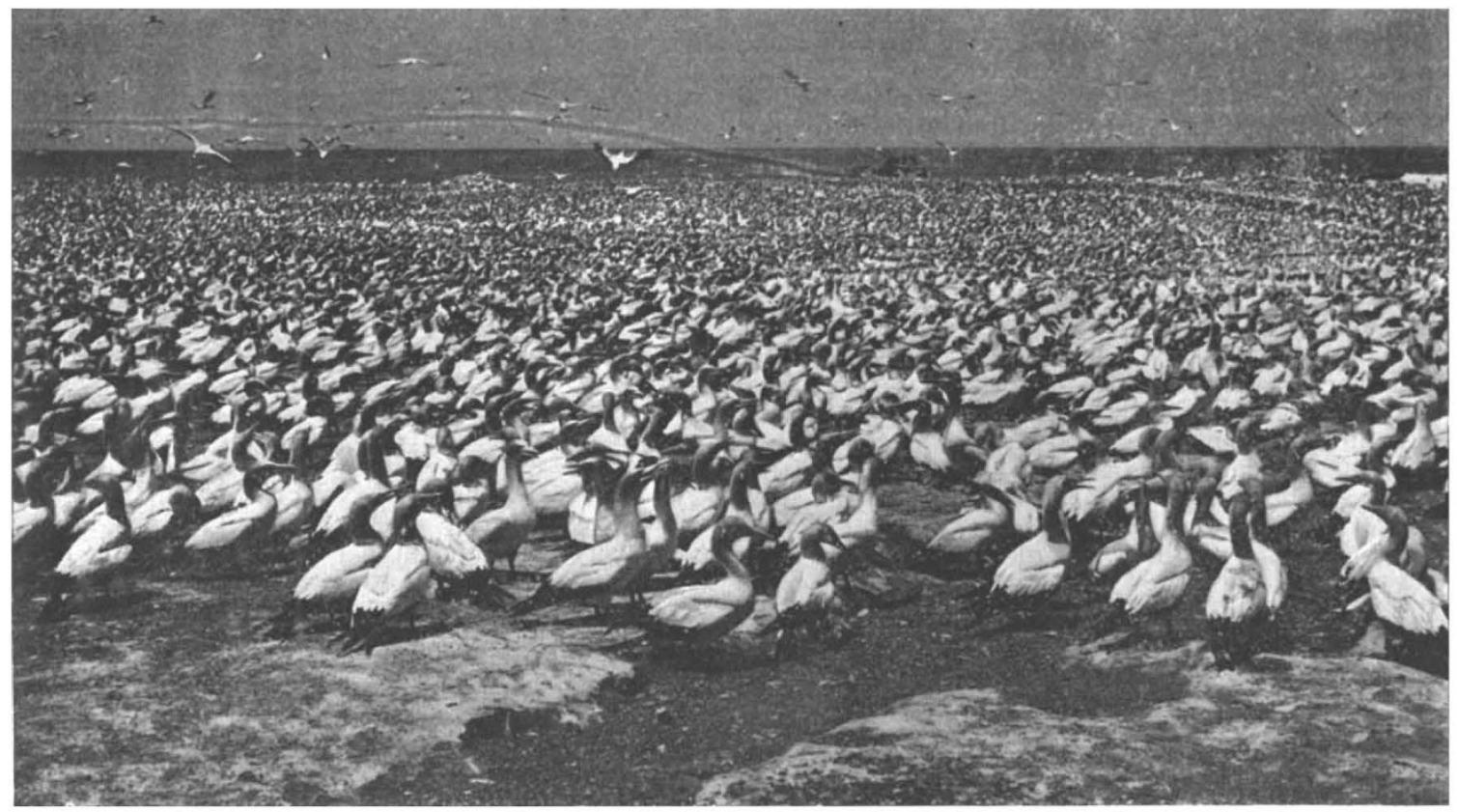

Cape Gannets on Bird Island.

the earth underneath them is loose also, and then you feel beneath the loose earth and there are two eggs!"

And yet it is difficult to account for this strange habit, since the eggs so closely resemble their surroundings that they would be passed unnoticed when lying on the bare ground. Often the nesting-site is in a locality much frequented both by men and cattle, and it is a marvel that all the eggs are not broken. On one occasion the author actually found an ox lying down on a nest whose situation was known to him ; strange to say, although one egg was crushed, the other was intact. The proceedings of the parent bird while thus effectually prevented from obtaining access to her nest are described with some humour by the author.

Many other anecdotes might be culled from Mr. Harris's pages, but enough has been said to indicate the interesting character of his work and the large amount of information with regard to the habits of birds that it contains. The author has been fortunate in obtaining the assistance of Mr. Howard Saunders in revising the NO. I 668, vOL. 64]
Mr. E. E. Glynn has investigated the relation between the Bacillus enteritidis sporogenes of Klein and diarrhœa. $\mathrm{He}$ has isolated this micro-organism from normal dejecta, dust, air, milk, and sugar, and has tested the effects of cultures upon guinea-pigs and upon himself by ingestion without evil result. He agrees with Dr. Hewlett that the Bacillus enteritidis sporogenes is a ubiquitous organism, and that there is at present no satisfactory evidence that it is a cause of diarrhoea.

Mr. A. T. MacConkey gives further details of his bilesalt lactose Agar medium for the isolation of $B$. coli and $B$. typhosus, for which purpose it seems to be a valuable addition to the methods hitherto in use. Mr. MacConkey also publishes a note on flagella staining, Mr. K. W. Monsarrat describes a primary malignant growth of the kidney, and Dr. Christophers discusses the prevention of malaria in Tropical Africa.

Enlargement of the spleen has been relied upon by many as the test of the prevalence of malaria in a listrict. but Dr. Daniels concludes that the spleen-test nay be 
worse tlan useless unless race and age are taken into accoumt.

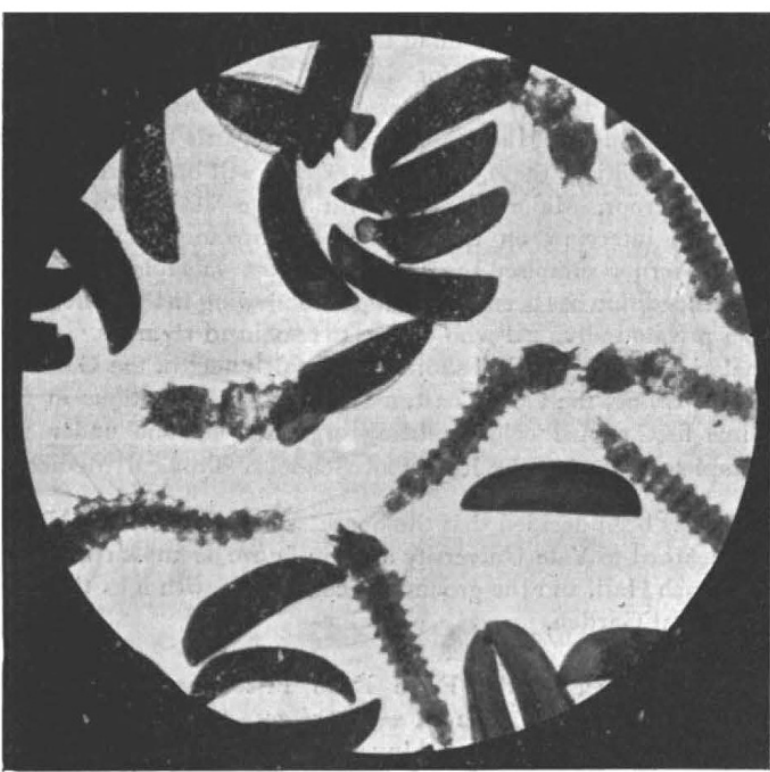

FIG. x.-Anopheles larve in several stages of their escape from the ova.

Two well-executed full-page diagrams by Messrs. Ross and Fielding-Ould illustrate the life-history of the
Nigeria of the Liverpool School of Tropical Medicine. The latter contains many good illustrations of the characteristics of the country and of the development of Anopheles. Two of these are here reproduced, one (Fig. I) showing Anopheles as ovum and larva, the other (Fig. 2) a breeding-ground of Anopheles.

A portrait and short obituary notice of the late Dr. Myers and an illustration of the Kanthack Medal in Pathology also appear in this volume. All the papers are valuable contributions to the science of medicine, and we shall look forward with interest to the publication of future volumes.

R. T. H.

\section{NOTES.}

THe Cape papers, says the Times, report the formation at Cape Town of a "South African Association for the Advance. ment of Science," to work as far as possible on the lines of the British Association. In July last a meeting was held to establish a congress of engineers, when an influential committee was appointed. The proposal gradually widened until at length it was found feasible to establish a local "British Association," and a meeting for that purpose, held under the chairmanship of Sir David Gill, F.R.S., the Astronomer Royal at the Cape Observatory, was largely attended, and the formation of the Association having been decided upon by formal vote, the title was discussed, "South African" being carried by $3 \mathrm{I}$ votes against 19 for "African."

A RevTer telegram of October I4 from Cape Town states that the Discovery sailed that day from Simon's Bay for Lyttelton, New Zealand.

THE resignation of $\mathrm{Dr}$. John Young, professor of natural history and lecturer in geology in the University of Glasgow, is announced. Dr. Young, who was appointed in I 866 to the professorship he now vacates, will retain his connection with the Hunterian Museum, of which he has for a number of years been curator.

Prof. JohN Joly, F.R.S., has, subject to the approval of the Lord Lieutenant, been co-opted to fill the vacancy on the Irish Lights Board caused by the death of Mr. J. Pim.

MR. J. R. JACKSON, who for a period of fortythree years has been asso. ciated with the Royal Gardens, Kew, has resigned the keepership of the Museum of Economic Botany, and is succeeded by Mr. J. M. Hillier, whose place, in turn, has butts

parasites of malaria, while the last half of the volume is occupied with the Report of the Malaria Expedition to NO. I 668 , VOL. 64$]$ 